Citation/Reference

Archived version

Published version

DOI

Journal homepage

Author contact
Ellen Rombouts, Bea Maes, \& Inge Zink

Quality of pantomime gestures relies on visuospatial skills Augmentative and Alternative Communication

Author manuscript: the content is identical to the content of the published paper, but without the final typesetting by the publisher

Accepted for publication on 18 May 2020

$\underline{A A C}$

ellen.rombouts@kuleuven.be 
Quality of Pantomime Gestures Relies on Visuospatial Skills

Ellen Rombouts, Bea Maes, and Inge Zink

KU Leuven

Author Note

Ellen Rombouts, Department of Neurosciences, Experimental Otorinolaryngology, KU Leuven, Belgium; Bea Maes, Parenting and Special Education Research Group, KU Leuven, Belgium; Inge Zink, Department of Neurosciences, Experimental Otorinolaryngology, KU Leuven, Belgium.

Correspondence concerning this article may be addressed to Ellen Rombouts, Experimental Otorinolaryngology, Herestraat 49 box 721, 3000 Leuven, Belgium. E-mail: ellen.rombouts@kuleuven.be

The first author is a Postdoctoral Fellow of the Research Foundation - Flanders (FWO, project number $12 \mathrm{Z} 5119 \mathrm{~N}$ - Cognitive skills and the gesture use and alignment in individuals with atypical development). We are very grateful to the FWO for their financial support. A special thank you to the children, parents, therapists, and teachers who made this study possible. There was no conflict of interest and there were no restrictions on the publication of results. The first author has full access to all the data in the study and takes responsibility for the integrity of the data and the accuracy of the data analysis. 


\begin{abstract}
While children with developmental language disorder and/or Williams syndrome both appear to use hand gestures to compensate for specific cognitive and communicative difficulties, they have different cognitive strength-weakness profiles. Their semantic and visuospatial skills potentially affect gesture quality such as iconicity. The present study focuses on untangling the unique contribution of these skills in the quality of gestures. An explicit gesture elicitation task was presented to 25 participants with developmental language disorder between 7 and 10 years of age, 25 age-matched peers with typical development, and 14 participants with Williams Syndrome ( 8 - 23 years). They gestured without using speech (pantomime) pictures of objects. The pantomimes' iconicity, semantic richness, and representation technique were coded. Participants' semantic association and visuospatial skills were formally assessed. Iconicity was slightly lower in individuals with Williams syndrome, which seems related to their visuospatial deficit. While semantic saliency was similar across participant groups, small differences in representation technique were found. Partial correlations showed that visuospatial skills and semantic skills were instrumental in producing clear pantomimes. These findings indicate that clinicians aiming to enhance individuals' natural iconic gestures should consider achieved iconicity, particularly in individuals with low visuospatial skills.
\end{abstract} Keywords: Iconic gesture; Williams syndrome; Language impairment; Cognitive skills 
Quality of Pantomime Gestures Relies on Visuospatial Skills

While speaking, individuals spontaneously produce hand movements that may depict content and/or serve a pragmatic function (Kendon, 2005). One subtype of hand gestures that depict content are iconic gestures. These gestures have strong communicative value because they entail a close visual resemblance between the manual modality and the concept that this gesture represents, making it easier to interpret (McNeil, 2000). Iconic gestures may facilitate communication in individuals with communication difficulties (Goldin-Meadow \& Alibali, 2013; Rose, Mok, \& Sekine, 2017). Because iconic gestures can encode information that is (partially) absent from speech, researchers have increasingly analyzed the use of gestures by participants with atypical language development, such as participants with developmental language disorder (e.g., Evans, Alibali, \& McNeil, 2001; Iverson \& Braddock; MainelaArnold, Alibali, Hostetter, \& Evans, 2014; Wray, Saunders, McGuire, Cousins, \& Norbury, 2017) and participants with Williams syndrome (Bello, Capirci, \& Volterra, 2004; Mastrogiuseppe \& Lee, 2017). Individuals with developmental language disorder and with Williams syndrome make more use of gestures that replace speech (Mastrogiuseppe \& Lee, 2017; Wray et al., 2017). In the present study, the role of cognitive skills in the iconicity of these participants' gestures is examined in the context of gestures that do not accompany speech (pantomimes).

Studies suggest that pantomime quality may be positively related to semantic association skills and visuospatial skills (Taub, 2001; van Nispen, van de Sandt-Koenderman, Mol, \& Krahmer, 2016; van Nispen, van de Sandt-Koenderman, \& Krahmer, 2017; Wray et al., 2017). While participants with developmental language disorder and Williams syndrome seem to use gestures to compensate for linguistic and cognitive difficulties (Bello et al., 2004; Evans et al., 2001; Iverson \& Braddock; Mainela-Arnold et al., 2014; Mastrogiuseppe \& Lee, 2017; Wray et al., 2017), they have different strength-weakness profiles with respect to these 
cognitive skills. It remains unclear how these skills affect the iconicity and quality of their gestures. Whereas participants with developmental language disorder have a significant language deficit and relatively spared performal IQ (Reilly et al., 2014), participants with Williams syndrome have mild or moderate intellectual disabilities with relatively spared language skills and a significant deficit in visuospatial skills (Farran \& Jarrold, 2003; Farran, Jarrold, \& Gathercole, 2001; Mervis \& John, 2008; Meyer-Lindenberg et al., 2004). It is unclear how their specific strength-weakness profiles affect the quality of their gestures. It is important that clinicians have insight into this influence because gesture quality is instrumental for achieving a facilitative effect on interpersonal communication (de Beer, Carragher, van Nispen, Hogrefe, \& de Ruiter, 2017; Sekine, Rose, Foster, Attard, \& Lanyon, 2013; Wilkinson, 2013; Wray et al., 2017).

To assess the iconic value of gestures, researchers have typically assessed the resemblance between the gesture and the concept by using gesture elicitation tasks where participants gesture objects without using speech (Botting, Riches, Gaynor, \& Morgan, 2010; van Nispen et al., 2016, 2017; Wray, Norbury, \& Alcock, 2016; Wray et al., 2017). In children with developmental language disorder, these studies have yielded diverging results. Botting et al. (2010) and Wray et al. (2016) showed pictures to participants with typical development and developmental language disorder and asked them to gesture what they saw. The authors rated on a Likert scale the resemblance between gesture and referent. While Botting et al. (2010) did not detect a significant difference in pantomime iconicity between children with developmental language disorder and typical development for each of the items, Wray et al. (2016) found that the former produced less iconic pantomimes than the latter. It is unclear how this difference may be explained considering that both studies used the same procedure and the participants had a similar mean age of 5;7 and 5;11 (years;months), respectively. We argue that between-group differences are valuable but also need additional 
analyses that account for potential within-group heterogeneity in cognitive profile.

Particularly in pantomime iconicity, these cognitive skills play an important role.

A conceptual framework by Taub (2001) explicates the cognitive steps that are involved in constructing an iconic pantomime (e.g., Emmorey, 2014; Ortega \& Özyürek, 2019; van Nispen et al., 2017). When individuals gesture a concept, they first access the concept and accompanying semantic features from semantic memory. Then, they select a mental visual image that depicts this concept. In a next step, individuals abstract this visual mental image into a visual scheme. For example, the image of a rhinoceros may be abstracted into four vertical legs and a horn. Finally, this abstract scheme is mapped onto hand movements. This framework gives a main role to two cognitive skills: semantic and visuospatial processing.

\section{Semantic Skills}

To our knowledge, there have been no studies on the relation between semantic skills and pantomimes in individuals with Williams syndrome and with developmental language disorder. Nevertheless, this is an important issue because both groups can have impaired lexico-semantic organization skills and often make more categorization errors (Haebig, Kaushanskaya, \& Weismer, 2015; Jarrold et al., 2000; Mainela-Arnold, Evans, \& Coady, 2010; Purser, Thomas, Snoxall, Mareschal, \& Karmiloff-Smith, 2011). Wray et al. (2017) found that the pantomimes of participants with developmental language disorder aged between 6 and 8 years were semantically weaker than the pantomimes of their peers with typical development, and they hypothesized that reduced semantic knowledge led to semantically weaker pantomimes. In line with Taub's model, reduced semantic processing may hinder the depiction of salient semantic features within pantomimes (Weidinger et al., 2017; Wray et al., 2017). Individuals with aphasia and impaired semantic processing have produced co-speech gestures and pantomimes that were less diverse and less iconic compared 
to individuals with intact semantic processing skills (Hogrefe, Ziegler, Weidinger, \& Goldenberg, 2012; van Nispen et al., 2016, 2017). Similarly, in primary-school children with typical development, increased encoding of distinct features in pantomimes correlated with higher performance on a semantic odd-one-out measure, suggesting that non-verbal semantic skills are instrumental in selecting salient features (Weidinger et al., 2017).

Semantic processing skills not only influence access to semantic information but also influence representation technique (Goldenberg, Hartmann, \& Schlott, 2003; Mol, Krahmer, \& van de Sandt-Koenderman, 2013; van Nispen et al., 2016; Weidinger et al., 2017). Different representation technique categorizations have been proposed but all categorizations are closely related (Ortega \& Özyürek, 2019). In studies involving adults with aphasia, van Nispen et al. $(2016,2017)$ have distinguished between shaping (moulding the object in the air), drawing (drawing contours in the air, typically with index finger), enacting (mimicking an activity that does not involve handling an object), handling (mimicking using an object), and object (the hand itself represents the object). A broader categorization is used in Ortega and Özyürek (2019), with four distinct categories: (a) acting (analogous to enacting and handling), (b) representing (analogous to object), (c) drawing (analogous to shaping and drawing), and (d) personification (mimicking an animal by physically adopting its features). Adults with aphasia and impaired semantic processing used representation techniques that required little semantic knowledge of the referent such as drawing or shaping the concept (Mol et al., 2013; van Nispen et al. 2016). Drawing an object is typically less understandable than, for example, mimicking the use of an object (Ortega \& Özyürek, 2019), which requires semantic knowledge.

One study suggests that the development of representation technique develops slower in children with developmental language disorder (Hill, Bishop, \& Nimmo-Smith, 1998). When pantomiming the use of an object, children with typical development between the ages 
of 3 and 9 years employed fewer object gestures and more handling gestures with increasing age (Boyatzis \& Watson, 1993; Dick, Overton, \& Kovacs, 2005; O’Reilly, 1995; Weidinger et al., 2017). Researchers have argued that older children use more handling pantomimes because they become more familiar with using these objects (Capone, 2007; Dick et al., 2005; Mizuguchi \& Sugai, 2002). In a task with verbal stimuli, children with developmental language disorder aged between 7 and 13 years $(M=9 ; 9$ years) made significantly more use of the object technique compared to age-matched peers but not compared to younger children aged between 5 and 6 years (Hill et al., 1998). This increased use of the object technique can indicate a delayed gesturing development as participants as are unable to make abstraction from the sensori-motor experience (Hill et al., 1998; Masson-Carro, Goudbeek, \& Krahmer, 2015). A strong focus on the object's shape without considering its associated action or handling suggests an inability to select the most salient semantic features of the concept to be gestured (van Nispen et al., 2016; Weidinger et al., 2017). Compared to the handling technique, the shaping, drawing, and object techniques rely more on visual perceptual features and less on semantic knowledge.

While Botting et al. (2010) found a correlation between pantomime iconicity and expressive vocabulary skills in children with developmental language disorder, Taub's model does not give a direct role to expressive language. Because reduced semantic knowledge and lexico-semantic processing can underlie a naming deficit, the result from Botting et al. (2010) may indicate the role of semantic processing rather than expressive language skills. In a study by van Nispen et al. (2016), pantomime iconicity in adults with aphasia, oral naming, and nonverbal semantic processing were all intercorrelated. In earlier studies on pantomime iconicity in children with developmental language disorder (Botting et al., 2010; Wray et al. 2016, 2017), no information was provided concerning the participants' semantic association skills. Diverging results from these studies may perhaps be explained through differences in 
semantic skills between the children with developmental language disorder from the different studies. Therefore, it is important to consider the role of semantic skills independent from expressive language skills.

\section{Visuospatial Skills}

In addition to semantic processing, Taub's gesture model (2001) gives a large role to manipulation of a visual mental image. Several other models rely on mental image activation during gesturing (de Ruiter, 2000; Hostetter \& Alibali, 2008; Kita, 2000). Children with developmental language disorder and with Williams syndrome experience difficulties with visuospatial processing. In the former children, storage and organization of visuospatial information develops in a delayed manner (Akshoomoff, Stiles, \& Wulfeck, 2006; Vugs, Cuperus, Hendriks, \& Verhoeven, 2013). This delay seems to increase with the severity of the language deficit (Vugs et al., 2013). In contrast to this delayed visuospatial processing, individuals with Williams syndrome have a significant deficit in their visuospatial construction skills relative to their intellectual functioning (Mervis \& John, 2008; MeyerLindenberg et al., 2004). They have performed variably on different visuospatial subtests and have typically achieved considerably low scores on the block design test (Farran \& Jarrold, 2003). Farran, Jarrold, and Gathercole (2001) attribute this to an inability to manipulate mental images. This ability plays a main role in Taub's model (2001), which raises the question whether reduced visuospatial skills negatively affect pantomime iconicity.

Presently, there are no clear results indicating that visuospatial skills may shape pantomime iconicity. In the gesturing study by Wray et al. (2017) children with developmental language disorder not only produced pantomimes with lower semantic saliency but they also had significantly lower results on the block design test compared to age-matched peers. Pantomime iconicity has correlated positively with nonverbal cognition in children with developmental language disorder and with typical development, both in Botting 
et al. (2010) where no between-group difference was found in pantomime iconicity and in Wray et al. (2016) where a between-group difference was found. While differences in gesture use between these two populations are typically attributed to language skills, Wray et al. (2017) noted that due to interrelatedness of various cognitive skills researchers cannot attribute these group differences to language skills when they do not control for visuospatial skills in their analyses. This implies that between-group analyses need to be complemented with correlational measures that account for the unique contribution of semantic association skills, expressive language skills, and visuospatial skills.

In the present study, we aimed to differentiate the influences from these skills on the quality of pantomimes in two participants groups who seem to use compensatory speechreplacing gestures (Mastrogiuseppe \& Lee, 2017; Wray et al., 2017) but have different cognitive profiles: participants with developmental language disorder and participants with Williams syndrome. To achieve this, between-group comparisons were combined with correlational measures that give insight into the unique contribution of these cognitive skills. First, we hypothesized that pantomimes have higher iconicity and higher semantic saliency in participants with developmental language disorder compared to participants with typical development (Wray et al. 2016; 2017). If semantic skills do not differ between participants with developmental language disorder and with Williams syndrome, then these variables are not expected to differ between these participant groups (Capone, 2007; Dick et al., 2005; Mizuguchi \& Sugai, 2002; Taub, 2001). A second hypothesis was that participants with developmental language disorder produce more object or shaping and fewer handling pantomimes compared to peers with typical development (Hill et al., 1998; Mol et al., 2013; van Nispen et al. 2016). If semantic skills do not differ between participants with developmental language disorder and with Williams syndrome, then representation technique is not expected to differ between these participant groups (Capone, 2007; Dick et al., 2005; 
Mizuguchi \& Sugai, 2002; van Nispen et al. 2016). A third hypothesis was that pantomime iconicity and semantic saliency are not correlated with expressive language skills but are positively correlated with semantic association skills (Taub, 2001; van Nispen et al. 2016). Considering lacking research on visuospatial skills, the hypothesis concerning its relation to pantomime iconicity is exploratory. It is expected that pantomime iconicity is positively related to visuospatial skills (Taub, 2001). Finally, we expected that the use of handling pantomimes would be positively related to semantic association skills whereas the use of object and drawing/shaping pantomimes would be inversely related (Capone, 2007; Dick et al., 2005; Mizuguchi \& Sugai, 2002; van Nispen et al. 2016).

\section{Method}

\section{Participants}

This study involved three groups of participants: (a) 25 with developmental language disorder aged between 7 and 9;11 (16 female, 9 male), (b) 25 with typical development matched for chronological age (17 female, 9 male), and (c) 14 with Williams syndrome (5 female, 9 male). The target was 20 participants per group. This target was based on earlier studies and feasibility (Botting et al., 2010; Mastrogiuseppe \& Lee, 2017; Wray et al., 2016). Because Williams syndrome is a rare condition, we only found 15 individuals who qualified for the study, and one individual chose not to participate. Inclusion criteria for participants with Williams syndrome were a genetically confirmed diagnosis of Williams syndrome and a chronological age between 8 and 23. The participants in this study were on average 13;11 (range 9;1 - 23) and had moderate intellectual disabilities.

Inclusion criteria for the participants with developmental language disorder were a diagnosis of developmental language disorder and chronological age between 7 and 9;11. The participants with developmental language disorder were on average $8 ; 10$ (range $7 ; 4-9 ; 10$ ). The diagnosis entailed that they had (a) no intellectual disability (i.e., performance IQ score 
above 85); no acquired neurological disorder, motor disorder, or psychological/psychiatric disorder; (b) at least one language subtest score below the 3rd percentile or two language subtest scores below the 10th percentile; and (c) a persistent language disorder with little improvement after nine months of intensive language therapy. Multilingualism was not an exclusion criterion. Exclusion criteria were diagnoses of autism or attention deficit disorder. For the participants with typical development there was one additional exclusion criterion: ever having received language therapy. They were matched for chronological age with the participants with developmental language disorder within a 3-month margin, as specified in the normative tables of the Peabody Picture Vocabulary Test -III- NL (PPVT-III-NL, Dunn \& Dunn, 2005).

The participants with developmental language disorder and with typical development were pairwise matched exclusively on chronological age. For this matching procedure, the age ranges from the PPVT normative tables because these represented the narrowest range (i.e., 3 months). The participants with Williams syndrome were not pairwise matched to children with developmental disorder because the rarity of the syndrome did not make this feasible. At group level, they could not be matched on chronological age due to the intellectual disabilities of the latter participants. To ensure that the latter group had similar verbal intelligence, a posthoc check was conducted using the PPVT-III-NL. This test does not measure verbal intelligence directly but is used here as a time-efficient test that correlates strongly with verbal intelligence (Dunn \& Dunn, 2005). Even though the age range was considerably larger in the participants with Williams syndrome, age equivalents scores were similar for the participants with developmental language disorder $(M=7 ; 2$ years, $M d n=7 ; 6$ years) and Williams syndrome ( $M=7 ; 6$ years, $M d n=7 ; 6$ years $)$.

Using convenience sampling, the first author recruited the participants with typical development and developmental language disorder by contacting schools. She contacted 
speech-language therapists of special education schools who then handed out the informed consent letter to all the parents of the children who qualified for the study. To recruit participants with Williams syndrome, the first author contacted the official organization for parents of children with Williams syndrome. Information was sent to all members via the organization's newsletter, and the first author attended a family day to inform parents. The parents of all participants gave informed written consent, and the first author obtained oral consent from the participants at the beginning of the data collection session.

Cognitive skills. During individual testing, the Semantic Association Test (SAT) was administered (Visch-Brink, Stronks, \& Denes, 2005). The SAT was developed for adults with aphasia. It was used because, unlike semantic subtests from WISC III-NL (Kort et al., 2005) and CELF-4-NL (Kort, Schittekatte, \& Compaan, 2010), it does not require verbal responses and it allows for graded scoring: (a) strong semantic relation (score of 3), (b) somewhat strong semantic relation (score of 2), (c) weak semantic relation (score of 1), and (d) no semantic relation (score of 0 ). This graded scoring with a maximum score of 90 was used during analyses. As illustrated in Table 1, the participants with developmental language disorder scored on average 2.84 fewer points $(S D=.90)$ than their age-matched peers, $t(48)=3.14, p=$ .003. Scores were similar for participants with developmental language disorder and Williams syndrome, $t(37)=.29, p=.153, M=.38, S D=1.29$.

To assess visuospatial skills, the Perceptual Organization Index from the WISC-III-NL was used. This Index is a composite score of four subtests: (a) picture completion, (b) picture arrangement, (c) block design, and (d) object assembly. While researchers have previously employed the block design test (Wray et al., 2017) and the Raven's coloured progressive matrices (Botting et al., 2010; Wray et al., 2016), a factor score such as the Perceptual Organization Index score is a more reliable measure than a single subtest score. In addition, individuals with Williams syndrome have considerable difficulty completing the block design 
test (Farran \& Jarrold, 2003; Farran et al., 2001), so that using only this subtest as a measure of visuospatial skills might have conflated the results. Because scores were lower than the scores provided in the manual's age equivalent table, the lower scores were calculated using the extrapolation method from Toffalini et al. (2019; see Appendix A for details). Table 1 shows that the visuospatial age equivalents of the participants with developmental language disorder were on average 26.2 months $(S D=5.53)$ less advanced than the participants with typical development, $t(48)=4.74, p<.001$. As expected, the visuospatial skills of the participants with Williams syndrome were on average 19.7 months $(S D=5.39)$ less advanced than the skills of the participants with developmental language disorder, $t(37)=.29, p=.001$.

Finally, expressive language was assessed using the Active Vocabulary subtest from the CELF-4-NL (Kort et al., 2010). Age equivalents were used because normative results from these tests are based on chronological age and could not be used for the individuals with Williams syndrome. The vocabulary skills of the participants with developmental language disorder were 38.7 months $(S D=4.52)$ less advanced compared to the participants with typical development, $t(48)=8.56, p<.001$, and 18.6 months $(S D=6.36)$ less advanced compared to the participants with Williams syndrome, $t(37)=-2.92, p=.006$.

In summary, the participants with developmental language disorder scored significantly lower on all measures compared to the participants with typical development. The results of the participants with developmental language disorder and with Williams syndrome showed reverse strength-weakness profiles that align with the characteristics of their diagnoses. While the children with developmental language disorder had more advanced visuospatial skills, their expressive language scores were lower compared to the children with Williams syndrome. Semantic skills were similar between these two groups.

\section{Research Design}


Required approvals were obtained from appropriate ethics boards. In a quasiexperimental design, pantomimes were elicited. In a between-group design, differences in pantomime iconicity, semantic saliency, and representational techniques were compared between participants with typical development and with developmental language disorder as well as between participants with developmental language disorder and with Williams syndrome. In addition, these dependent variables were related to the individual scores on the SAT, Active Vocabulary subtest, and the Perceptual Organization factor from the WISC.

\section{Materials}

For the gesture elicitation task, the picture items from van Nispen et al. $(2016,2017)$ were adopted. In their pantomime task, they showed 30 pictures of objects from the Boston Naming Task (Kaplan, Goodglass, \& Weintraub, 1983). For the present study, 20 items were selected because Botting et al. (2010) found that this was a feasible number of items for participants in this age group and because some items were assumed unfamiliar to primary school children. As an indicator of an item's familiarity, the target vocabulary list for 6-yearolds was used (Schaerlaekens, Kohnstamm, \& Lejaegere, 2000). This source summarizes survey data from teachers and lists Dutch words together with the percentage of 6-year-old children that are estimated to comprehend each word. Items that were absent from the survey were excluded, which left 18 items. To obtain 20 items, the pictures TENNIS RACKET and PELICAN were included due to their close associations with the listed words tennis and bird, which $84 \%$ and $98 \%$ of teachers estimated were familiar to the 6 -year-old children.

\section{Procedures}

Data collection. In two sessions, data were collected for four different studies focusing on different aspects of gesture use and gesture adoption. Each session lasted about 90 minutes. To keep participants motivated and enthusiastic, tasks were varied. Next to the cognitive measures and gesture elicitation task,. we also collected data from narrative tasks by 
showing four cartoons, but in the present study we will exclusively focus on the gesture elicitation task. During the first session the following tasks were presented in a fixed order: PPVT, CELF Active Vocabulary subtest, cartoon, WISC 2 subtests, cartoon, WISC 2 subtests. During the second session, the participants completed the following sequence: SAT, cartoon, CELF Formulating Sentences subtest, cartoon, gesture elicitation task.

The gesture elicitation procedure was based on earlier studies (Botting et al., 2010; van Nispen et al., 2016, 2017; Wray et al., 2016). The participant stood opposite the researcher. The researcher had a laptop on her lap, with the screen directed towards the participant. On the screen, picture items appeared one by one. The researcher explained that she could not see the screen. She wore headphones and explained that she could not hear what the participant said because music was playing through the headphones (Botting et al., 2010). In a playful set-up, participants needed to describe what they saw by using gestures so that the researcher could guess the picture. When gesturing was difficult, the researcher would encourage the child to undertake multiple attempts. In addition, the researcher occasionally made wrong guesses in order to encourage the child to undertake an additional attempt.

Data coding and reliability. Similar to earlier studies (Botting et al., 2010; Wray et al. 2016), the first author and three research assistants, three speech-language pathology students, independently assessed each pantomime's iconicity using a Likert scale ranging from a score of 1 (no apparent relation between gesture and concept) to 5 (very clear relation between gesture and concept). In addition, semantic saliency was coded for each gesture using a self-developed coding scheme whereby each gesture received a saliency score between 0 and 2 (see Appendix B). Finally, the first author coded representation technique for each performed gesture and hereby distinguished between handling/enacting, object, and drawing/shaping (Ortega \& Özyürek, 2019). Animal personifications were coded as object gestures. For interrater reliability purposes, one research assistant independently coded 
semantic saliency and representation technique for $66 \%$ of the pantomimes. The first author and research assistant achieved a moderate agreement with Cohen kappa $=.645(80.53 \%$ agreement) for semantic saliency agreement and with Cohen kappa $=.755(85.26 \%$ agreement) for representation technique.

Data analysis. Independent variables were: the group distinction, semantic association skills (SAT score), expressive language skills (active vocabulary age equivalent), and visuospatial skills (WISC perceptual organization, age equivalent). Dependent variables were pantomime iconicity, semantic saliency, and representation technique. An iconicity score was calculated per participant based on the Likert ratings from the researchers. Per pantomime that a participant made, we averaged the Likert ratings from the four raters by adding them and dividing them by 4 . To obtain one iconicity score per participant, these averaged scores for the 20 pantomimes were added per participant. This total iconicity score per participant had a minimum of 20 and a maximum of 100 as the rating scale ranged between 1 and 5 . The semantic saliency score was the sum of the semantic saliency scores per child (maximum score of 40). To analyze representation technique, the number of shaping/drawing gestures, of object gestures, and handle/enact gestures was added per participant.

Statistical analyses were performed with SPSS. Shapiro-Wilk testing and visual examination of Q-Q plots demonstrated that the dependent variables did not have a normal distribution. Non-normal data distributions as well as interactions between diagnosis and cognitive skills meant that an ANCOVA model or linear regression could not be constructed (see also Wray et al., 2017). Using the non-parametric Mann Whitney $U$ test, two betweengroup analyses were conducted for each of the three dependent variables: typical development compared to developmental language disorder, and developmental language disorder compared to Williams syndrome. Following the recommendation in Fritz, Morris and Reichler (2012), the effect size $r$ was used. To examine the relation between the dependent 
variables and the measured cognitive skills, partial Spearman correlations were calculated. Due to strong intercorrelations between the semantic, expressive language, and visuospatial skills, each partial correlation controlled for the other two cognitive skills.

\section{Results}

Between-group comparisons were conducted with the three dependent variables: pantomime iconicity, semantic saliency, and representation technique. As shown in Figure 1, participants with typical development and developmental language disorder did not differ in pantomime iconicity, $U=247.50, p=.293$, but the latter had slightly higher iconicity ratings than the participants with Williams syndrome, $U=67.50, p=.002$. The semantic saliency score did not differ between participants with typical development and developmental language disorder, $U=284.50, p=.756$, or between participants with developmental language disorder and Williams syndrome, $U=148.50, p=.560$. As illustrated in Table 2, participants with typical development and developmental language disorder produced handle/enact strategies to the same extent, $U=292.50, p=.880$. While participants with developmental language disorder used more draw/shape gestures than the participants with typical development, $U=195.50, p=.034$, the former produced more object strategies, $U=$ $172.00, p=.009$. In contrast, representation techniques did not differ between participants with developmental language disorder and with Williams syndrome, .087 $<p<.731$.

Correlational analyses were conducted to examine the contribution of semantic, expressive language, and visuospatial skills in pantomime quality. Partial Spearman correlations showed that, as illustrated in Figure 2, pantomime iconicity had a positive relation with perceptual organization, $r_{s}=.442, p<.001,95 \%$ CI $[.218, .622]$. Pantomime iconicity had a borderline significant positive relation with semantic skills when controlling for active vocabulary, $r_{s}=.244, p=.056,95 \%$ CI [-.004, .464], but this correlation disappeared when also controlling for perceptual organization, $r_{s}=.154, p=.237$. A 
significant correlation between pantomime iconicity and active vocabulary, $r=.291, \mathrm{p}=.021$, 95\% CI [.047, .503], disappeared when controlling for semantic association, $r_{s}=.149, p<$ .248. Semantic saliency correlated significantly with pantomime iconicity, $r_{s}=.705, p<.001$, $95 \% \mathrm{CI}[.554, .811]$, and semantic association, $r_{s}=.350, p<.005,95 \% \mathrm{CI}[.112, .550]$, but not expressive vocabulary, $r_{s}=.223 ; p=.079$, or perceptual organization, $r_{s}=.198 ; p=.120$. Representation technique did not significantly correlate with semantic association.

\section{Discussion}

Even though individuals with developmental language disorder and with Williams syndrome use speech-replacing gestures (Mastrogiuseppe \& Lee, 2017; Wray et al., 2017), little is known about how their cognitive skills shape the iconicity of these gestures. This iconicity is instrumental in facilitating interactions (Rose et al., 2017). Studies on iconicity of their pantomimes have yielded diverging results for the former participant group (Botting et al., 2010; Wray et al., 2016) and have not yet been conducted for the latter group. Unraveling how semantic processing, expressive language, and visuospatial skills each contribute to individuals' quality of pantomimes may give insight into these diverging results. In addition, these factors can guide gesture intervention research, e.g., addressing cognitive skills during gesture intervention to bolster gesture iconicity or identifying participants who are more likely to benefit from gesture intervention.

In line with Wray et al. $(2016,2017)$, it was expected that pantomimes of participants with developmental language were less iconic compared to participants with typical development. However, similar to the findings from Botting et al. (2010), the present participants with developmental language disorder did not produce pantomimes that were less iconic than the pantomimes of age-matched peers with typical development. Nevertheless, individual results also provide some support for Wray et al. (2016). The data of the participants with developmental language disorder showed a larger spread towards the lower 
end of the Likert rating. Participants with Williams syndrome produced pantomimes that were lower in iconicity compared to participants with developmental language disorder. While it was expected that iconicity would be similar considering that these participant groups had similar semantic association test scores, the visuospatial deficit may have affected pantomime iconicity.

Supporting Taub's model (2001), correlation analyses showed that visuospatial skills correlated with pantomime iconicity. This finding may account for earlier diverging results concerning the pantomime iconicity of participants with developmental language disorder (Botting et al., 2010; Wray et al. 2016) and may also explain the present between-group results. Compared to participants with typical development, the participants with developmental language disorder not only demonstrated a larger spread towards lower Likert ratings but also towards lower visuospatial skills. Furthermore, individuals with Williams syndrome had both significantly lower pantomime iconicity and significantly lower visuospatial skills. Subgroup trends in Figure 2 suggest that the relation between visuospatial skills and gesture iconicity was particularly important as visuospatial skills decreased. The data from the participants with Williams syndrome were grouped in the lower end of the visuospatial skills and of the gesture iconicity. It is remarkable that participants with Williams syndrome differed with respect to iconicity but not semantic saliency or representation technique. Based on the correlation with visuospatial skills, one hypothesis is that their visuospatial skills affected the motor accuracy of their pantomimes. In children with Williams syndrome, an association has been found between visuospatial skills and motor coordination (Heiz \& Barisnokov, 2016).

While semantic saliency did not differ between the participant groups, a small difference in representation technique was found. Participants with developmental language disorder used slightly more draw/shape gestures than participants with typical development 
who used more object gestures. On the one hand, this finding contrasts with Hill et al. (1998) who found that participants with developmental language disorder used more object gestures. One significant difference is that the participants in the present study are older. Perhaps, participants with developmental language disorder have caught up any delayed gesturing development by the age of 7 . On the other hand, the trade-off between object and handle pantomimes found in Hill et al. (1998) seems to have shifted towards draw/shape and object gestures; using relatively more draw/shape gestures also requires less semantic knowledge (van Nispen et al., 2016). Nevertheless, the lack of a correlation between semantic skills and representation technique cautions against interpreting this between-group difference in light of semantic knowledge. The lack of this influence may also have been caused by the less severe impaired semantic processing of the present participants.

While the semantic association test scores were not directly related to pantomime iconicity, they echoed results from research in adults with aphasia and children with typical development as they showed a moderate positive correlation with gestural semantic saliency that in turn correlated strongly with pantomime iconicity (Hogrefe et al., 2012; van Nispen et al., 2016, 2017; Weidinger et al., 2017). In contrast to the findings from van Nispen et al. (2016), the slightly higher use of shaping pantomimes by participants with developmental language disorder was not associated with semantic processing skills. A possible explanation may lie in the choice of test. While the present SAT scores $(M d n=26)$ and the SAT scores from the persons with aphasia $(M d n=27.5)$ in the study by van Nispen et al. did not significantly differ, $U=1198.50, p=.90$, the minimum score varied strongly with a score of $21 / 30$ in the present study and a score of $6 / 30$ in the study by van Nispen et al. This leaves the possibility that semantic processing affects pantomime iconicity primarily when semantic processing is severely compromised.

\section{Clinical Implications}


The present findings underscore the importance of considering individuals' visuospatial skills and to lesser extent semantic skills when encouraging natural gestures. Clinicians who encourage individuals with language difficulties to use natural gestures should consider the level of visuospatial skills. Individuals who have weak visuospatial skills, such as participants with Williams syndrome and with developmental language disorder who have weaker visuospatial skills, may produce more speech-replacing gestures with lower iconicity. Nevertheless, it remains unclear how exactly visuospatial skills affect gesture iconicity and how closely this relation is linked to motor coordination. While the present study does not indicate that the iconicity is too low to negatively impact functional communication, it is important to consider that gesture use in these children may be more difficult.

\section{Limitations and Future Directions}

Two main limitations concern the pantomime procedure and the statistical procedure. During the pantomime task, participants were encouraged to try multiple attempts if they found gesturing difficult. The results could have been different if the researchers had rated the first rather than the best attempt. In addition, no script was in place for the playful wrong guesses of the researcher. Consequently, it cannot be ruled out that these guesses guided the participants towards producing more semantically salient gestures. Because gesture iconicity is very difficult to assess in co-speech gestures due to the close relation to speech, an artificial task was adopted. The artificial nature of the task limits generalizability to natural contexts. Nevertheless, this study gives a first indication concerning which individuals may need additional support during a gesture intervention and which cognitive skills may facilitate this process. Gesture use involves much more than iconicity. The facilitatory effect also relies on how participants employ gestures within a given linguistic and communicative context (Wray

et al., 2017) and how these gestures help listeners to understand the message. Further study of the present participants' use of speech-replacing gestures in a communicative context is 
warranted to gain further insight into its facilitative effect and how this effect may be increased.

Because the data were not normally distributed, it was not possible to conduct ANCOVA or linear regression. Due to non-normal distribution, these analyses were split into between-group testing and correlational analyses. By using simple tests, statistical power was increased but it also meant that interpretation was based on combining different test results rather than relying on one exhaustive statistical test. Based on earlier studies and feasibility, the preset target was 20 participants in each group. For a Mann Whitney $U$ test to detect a large effect size with power 0.8 , each group should contain 27 participants. Therefore, when the chance arose, more participants were included in the study so that 25 participants were achieved in two groups. Unfortunately, even though recruiting of participants with Williams syndrome was efficient thanks to the collaboration of the parent organization, only 14 participants were included. To indicate the results' reliability, confidence intervals have been included. Correlation analyses per group were not possible because this would have entailed a significant reduction in statistical power. It remains possible that relations between cognitive skills, gesture iconicity, and gesture use differ between the groups.

\section{Conclusion}

Pantomime iconicity was significantly lower in individuals with Williams syndrome and in some children with developmental language disorder. In line with Taub's model (2001), visualization and semantic association skills positively affected pantomime iconicity. The lower visuospatial skills of these participants seemed to be associated with lower pantomime iconicity. Even though they had pictures to start from, their ability to mentally manipulate visual information strongly affected gesture iconicity. The lower pantomime iconicity of participants with Williams syndrome compared to participants with developmental language disorder was not accompanied by a significant difference in the 
pantomimes' semantic saliency. Nevertheless, across all groups pantomime iconicity rose significantly as participants encoded more distinct semantic features. While participants with developmental language disorder did not produce less iconic or semantically weaker pantomimes compared to participants with typical development, a small difference in representation technique suggests that the former have a slightly delayed gesturing development. Due to the artificial nature of this task, additional study research is needed on the iconicity and quality of speech-replacing gestures that participants produce during speech. As Wray et al. (2017) aptly wrote, it is all about the quality of gestures. 


\section{References}

Akshoomoff, N., Stiles, J., \& Wulfeck, B. (2006). Perceptual organization and visual immediate memory in participants with specific language impairment. Journal of the International Neuropsychological Society, 12, 465-474.

Doi:10.1017/S1355617706060607

Bello, A., Capirci, O., \& Volterra, V. (2004). Lexical production in participants with Williams syndrome: Spontaneous use of gesture in a naming task. Neuropsychologia, 42, 201213. Doi:10.1016/S0028-3932(03)00172-6

Botting, N., Riches, N., Gaynor, M., \& Morgan G. (2010). Gesture production and comprehension in participants with specific language impairment. British Journal of Developmental Psychology, 21, 51-69. Doi: 10.1348/026151009X482642

Boyatzis, C. J., \& Watson, M. W. (1993). Preschool participants's symbolic representation of objects through gestures. Child Development, 64, 729-735. Doi: 10.2307/1131214

Capone, N.C. (2007). Tapping toddlers' evolving semantic representation via gesture. Journal of Speech, Language, and Hearing Research, 50, 732-745. Doi: 10.1044/1092$4388(2007 / 051)$

de Beer, C., Carragher, M., van Nispen, K., Hogrefe, K., de Ruiter, J.P., \& Rose, M.L. (2017). How much information do people with aphasia convey via gesture? American Journal of Speech-Language Pathology, 26, 483-497. Doi: 10.1044/2016_AJSLP-15-0027

de Ruiter, J. P. (2000). The production of gesture and speech. In D. McNeill (Ed.), Language \& Gesture (pp. 284-311). Cambridge, United Kingdom: Cambridge University Press.

Dick, A.S., Overton, W.F., \& Kovacs, S.L. (2005). The development of symbolic coordination: Representation of imagined objects, executive function, and theory of mind. Journal of Cognition and Development, 6, 133-162. Doi:

$10.1207 / \mathrm{s} 15327647 \mathrm{jcd} 0601 \_8$ 
Dunn, L.M, \& Dunn, D.M. (2005). Peabody Picture Vocabulary Test III- NL. Amsterdam, The Netherlands: Pearson Assessment.

Emmorey, K. (2014). Iconicity as structure mapping. Philosophical Transactions of the Royal Society B, 369: 20130301. Doi: 10.1098/rstb.2013.0301

Evans, J.A., Alibali, M.W., \& McNeil, N.M. (2001). Divergence of verbal expression and embodied knowledge: Evidence from speech and gesture in participants with specific language impairment. Language and Cognitive Processes, 16, 309-331. Doi: $10.1080 / 01690960042000049$

Farran, E.K., \& Jarrold, C. (2003). Visuospatial cognition in Williams syndrome: Reviewing and accounting for the strengths and weaknesses in performance. Developmental Neuropsychology, 23, 173-200. Doi: 10.1080/87565641.2003.9651891

Farran, E.K., Jarrold, C., \& Gathercole, S.E. (2001). Block design performance in the Williams syndrome phenotype: A problem with mental imagery? The Journal of Child Psychology and Psychiatry and Related Disciplines, 42, 719-728. Doi:

$10.1017 / \mathrm{S} 0021963001007429$

Fritz, O.F., Morris, P.E., \& Reichler, J.J. (2012). Effect size estimates: Current use, calculations, and interpretation. Journal of Experimental Psychology, 141, 2-18. Doi: $10.1037 / \mathrm{a} 0024338$

Goldenberg, G., Hartmann, K., \& Schlott, I. (2003). Defective pantomime of object use in left brain damage: Apraxia or asymbolia? Neuropsychologia, 41, 1565-1573. Doi: $10.1016 / \mathrm{S} 0028-3932(03) 00120-9$

Goldin-Meadow, S., \& Alibali, M.W. (2013). Gesture's role in speaking, learning, and creating language. Annual Review of Psychology, 64, 257-283.

Haebig, E., Kaushankskaya, M., \& Weismer, S. (2015) Lexical processing in school-age participants with autism spectrum disorder and participants with specific language 
impairment: The role of semantics. Journal of Autism and Developmental Disorders, 45, 4109-4123. Doi: 10.1007/s10803-015-2534-2

Heiz, J., Bariznikov, K. (2016). Visual-motor integration, visual perception and motor coordination in a population with Williams syndrome and in typically developing children. Journal of Intellectual Disability Research, 60, 945-955. Doi:

$10.1111 /$ jir. 12328

Hill, E.L., Bishop, D.V.M., \& Nimmo-Smith, I. (1998). Representational gestures in Developmental Coordination Disorder and specific language impairment: Error-types and the reliability of ratings. Human Movement Science, 17, 655-678. Doi: $10.1016 / \mathrm{S} 0167-9457(98) 00017-7$

Hogrefe, K., Ziegler, W., Weidinger, N., \& Goldenberg, G. (2011). Non-verbal communication in severe aphasia: Influence of aphasia, apraxia, or semantic processing? Cortex, 48, 952-962. Doi: 10.1016/j.cortex.2011.02.022

Hostetter, A.B., \& Alibali, M. (2008). Visible embodiment: Gestures as simulated action. Psychonomic Bulletin \& Review, 15, 495-514. Doi: 10.3758/PBR.15.3.495

Iverson, J.M., \& Braddock, B.A. (2011). Gesture and motor skill in relation to language in participants with language impairment. Journal of Speech, Language, and Hearing Research, 54, 72-86. Doi: 10.1044/1092-4388(2010/08-0197)

Kaplan, E., Goodglass, H., \& Weintraub, S. (1983). The Boston Naming Test. Philadelphia, PA: Lea \& Febiger.

Kendon, A. (2005). Visible action as utterance. Cambridge, Mass: Cambridge University Press.

Kita, S. (2000). How representational gestures help speaking. In D. McNeill (Ed.), Language and gesture. Cambridge University Press. 
Kort, W., Schittekatte, M., Dekker, P.H., Verhaeghe, P., Compaan, L.E., Bosmans, L., \& Vermeir, G. (2005). Wechsler Intelligence Scale for Participants III - NL. London: Pearson Assessment.

Kort, W., Schittekatte, M., \& Compaan, E. (2010). CELF-4-NL: Clinical Evaluation of Language Fundamentals-4-NL. Amsterdam, The Netherlands: Pearson Assessment.

Mainela-Arnold, E., Alibali, M.W., Hostetter, A.B., \& Evans, J.L. (2014). Gesture-speech integration in participants with specific language impairment. International Journal of Language \& Communication Disorders, 49, 761-770. Doi: 10.111/1460-6984.12115

Mainela-Arnold, E., Evans, J.L., \& Coady, J.A. (2010). Explaining lexical-semantic deficits in specific language impairment: the role of phonological similarity, phonological working memory, and lexical competition. Journal of Speech, Language, and Hearing Research, 53, 1742-1756. Doi: 10.1044/1092-4388(2010/08-0198)

Masson-Carro, I., Goudbeek, M., \& Krahmer, E. (2015). Coming of age in gesture: A comparative study of gesturing and pantomiming in older children and adults. In Proceedings of the 4th GESPIN - Gesture \& Speech in Interaction Conference.

Mastrogiuseppe, M., \& Lee, S.A. (2017). What gestures reveal about cognitive deficits in Williams syndrome. Developmental Neuropsychology, 42, 470-481. Doi: $10.1080 / 87565641.2017 .1393685$

McNeill, D. (2000). Language and Gesture. Cambridge, United Kingdom: Cambridge University Press.

Mervis, C.B., \& John, A.E. (2008). Vocabulary abilities of participants with Williams syndrome: Strengths, weaknesses, and relation to visuospatial construction ability. Journal of Speech, Language, and Hearing Research, 51, 967-982. Doi: $10.1044 / 1092-4388(2008 / 071)$ 
Meyer-Lindenberg, A., Kohn, P., Mervis, C.B., Kippenhan, J.S., Olsen, R.K., Morris, C.A., \& Berman, K.F. (2004). Neural basis of genetically determined visuospatial construction deficit in Williams syndrome. Neuron, 43, 623-631. Doi:

10.1016/j.neuron.2004.08.014

Mizuguchi, T., \& Sugai, K. (2002). Object-related knowledge and the production of gestures with imagined objects by preschool participants. Perceptual and Motor Skills, 94, 7179. Doi: 10.2466/PMS.94.1.71-79

Mol, L., Krahmer, E., \& van de Sandt-Koenderman, W. M. E. (2013). Gesturing by speakers with aphasia: How does it compare? Journal of Speech, Language, and Hearing Research, 56, 1224-1236. Doi: 10.1044/1092-4388(2012/11-0159)

Ng, K.Y., \& Jun, J.H. [CGIMeetUp]. (2017, 10 10). Love on the Balcony. Retrieved from https://www.youtube.com/watch?v=OaOmOi3EOcA

O'Reilly, A.W. (1995). Comprehension and production of actions with imagined objects. Child Development, 66, 999-1010. Doi: 10.2307/1131794

Ortega, G., \& Özyürek, A. (2019). Systematic mappings between semantic categories and types of iconic representations in the manual modality: A normed database of silent gesture. Behavior Research Methods. Doi: 10.3758/s13428-019-01204-6

Purser, H.R.M., Thomas, M.S.C., Snoxall, S., Mareschal, D., \& Karmiloff-Smith, A. (2011). Definitions versus categorization: assessing the development of lexico-semantic knowledge in Williams syndrome. International Journal of Language and Communication Disorders, 46, 361-373. Doi: 10.3109/13682822.2010.497531

Reilly, S., Tomblin, B., Law, J., McKean, C., Mensah, F.K., Morgan, A., ..., Wake, M. (2014). Specific language impairment: A convenient label for whom? International Journal of Language \& Communication Disorders, 49, 416-451. Doi: 10.1111/14606984.12102 
Rose, M.L., Mok, Z., \& Sekine, K. (2017). Communicative effectiveness of pantomime gesture in people with aphasia. International Journal of Language \& Communication Disorders, 52, 227-237. Doi: 10.1111/1460-6984.12268

Schaerlaekens, A., Kohnstamm, D., \& Lejaegere, M. (2000). Streeflijst woordenschat voor zesjarigen [Target vocabulary list for six-year-olds]. Lisse: Swets \& Zeitlinger.

Sekine, K., Rose, M. L., Foster, A. M., Attard, M. C., \& Lanyon, L. E. (2013). Gesture production patterns in aphasic discourse: In-depth description and preliminary predictions. Aphasiology, 27, 1031-1049. Doi: 10.1080/02687038.2013.803017

Taub, S. F. (2001). Language from the body: Iconicity and metaphor in American Sign Language. Cambridge, United Kingdom: Cambridge University Press.

Toffalini, E., Buono, S., Zagaria, T., Calcagni, A., \& Cornolodi, C. (2019). Using Z and ageequivalent scores to address WISC-IV floor effects for participants with intellectual disability. Journal of Intellectual Disability Research, 63, 528-538. Doi: $10.1111 /$ jir.12589

van Nispen, K., van de Sandt-Koenderman, M., Mol, L., \& Krahmer, E. (2016). Pantomime production by people with aphasia: What are influencing factors? Journal of Speech, Language, and Hearing Research, 59, 745-758. Doi:10.1044/2015_JSLHR-L-15-0166 van Nispen, K., van de Sandt-Koenderman W.M.E., \& Krahmer, E. (2017). Production and comprehension of pantomimes used to depict objects. Frontiers in Psychology, 8:1095. Doi: 10.3389/fpsyg.2017.01095.

Visch-Brink, E., Stronks, D., \& Denes, G. (2005). De semantische associatie test [The semantic association test]. Amsterdam: Harcourt.

Vugs, B., Cuperus, J., Hendriks, M., \& Verhoeven, L. (2013). Visuospatial working memory in specific language impairment: A meta-analysis. Research in Developmental Disabilities, 34, 2586-2597. Doi: 10.1016/j.ridd.2013.05.014 
Weidinger, N., Lindner, K., Hogrefe, K., Ziegler, W., \& Goldenberg, G. (2017). Getting a grasp on participants's representational capacities in pantomime of object use. Journal of Cognition and Development, 18, 246-269. Doi: 10.1080/15248372.2016.1255625

Wilkinson, R. (2013). Gestural depiction in acquired language disorders: On the form and use of iconic gestures in aphasic talk-in-interaction. Augmentative \& Alternative Communication, 29, 68-82. Doi: 10.3109/07434618.2013.767558

Wray, C., Norbury, C.F., \& Alcock, K. (2016). Gestural abilities of participants with specific language impairment. International Journal of Language \& Communication Disorders, 51, 174-182. Doi: 10.1111/1460-6984.12196

Wray, C., Saunders, N., McGuire, R., Cousins, G., \& Norbury, C.F. (2017). Gesture production in language impairment: It's quality, not quantity, that matters. Journal of Speech, Language, and Hearing Research, 60, 969-982. Doi: 10.1044/2016_JSLHRL-16-0141 
Table 1

The Average, Minimum, and Maximum Scores for the Semantic Association Test Score and Aqe Equivalents (in months) on Expressive Language and Visuospatial Skills

\begin{tabular}{lccc}
\hline Participant group & $\begin{array}{c}\text { Semantic } \\
\text { association }\end{array}$ & $\begin{array}{c}\text { Active } \\
\text { vocabulary }\end{array}$ & $\begin{array}{c}\text { Perceptual } \\
\text { organization }\end{array}$ \\
\hline Typically developing & $86.36(77,90)$ & $102.88(75,130)$ & $112.2(81,163)$ \\
Developmental language disorder & $83.53(75,89)$ & $64.20(36,100)$ & $86.0(58,118)$ \\
Williams syndrome & $83.14(73,89)$ & $82.79(36,130)$ & $66.29(43,90)$ \\
\hline
\end{tabular}


Table 2

Median Scores for Pantomime Iconicity, Semantic Saliency and Representation Technique per Participant Group

\begin{tabular}{lccc}
\hline Dependent variable & $\begin{array}{c}\text { Typically } \\
\text { developing }\end{array}$ & $\begin{array}{c}\text { Developmental } \\
\text { language disorder }\end{array}$ & $\begin{array}{c}\text { Williams } \\
\text { syndrome }\end{array}$ \\
\hline Pantomime iconicity & 3.90 & $\mathbf{3 . 7 4}$ & $\mathbf{3 . 0 6}$ \\
Semantic saliency & 29.00 & 29.50 & 29.50 \\
Handle/enact strategy & 11 & 12 & 11 \\
Object strategy & $\mathbf{6}$ & $\mathbf{4}$ & 5 \\
Draw/shape strategy & $\mathbf{2}$ & $\mathbf{4}$ & 4 \\
\hline
\end{tabular}

Note. The figures in bold represent between-group results that significantly differ. 


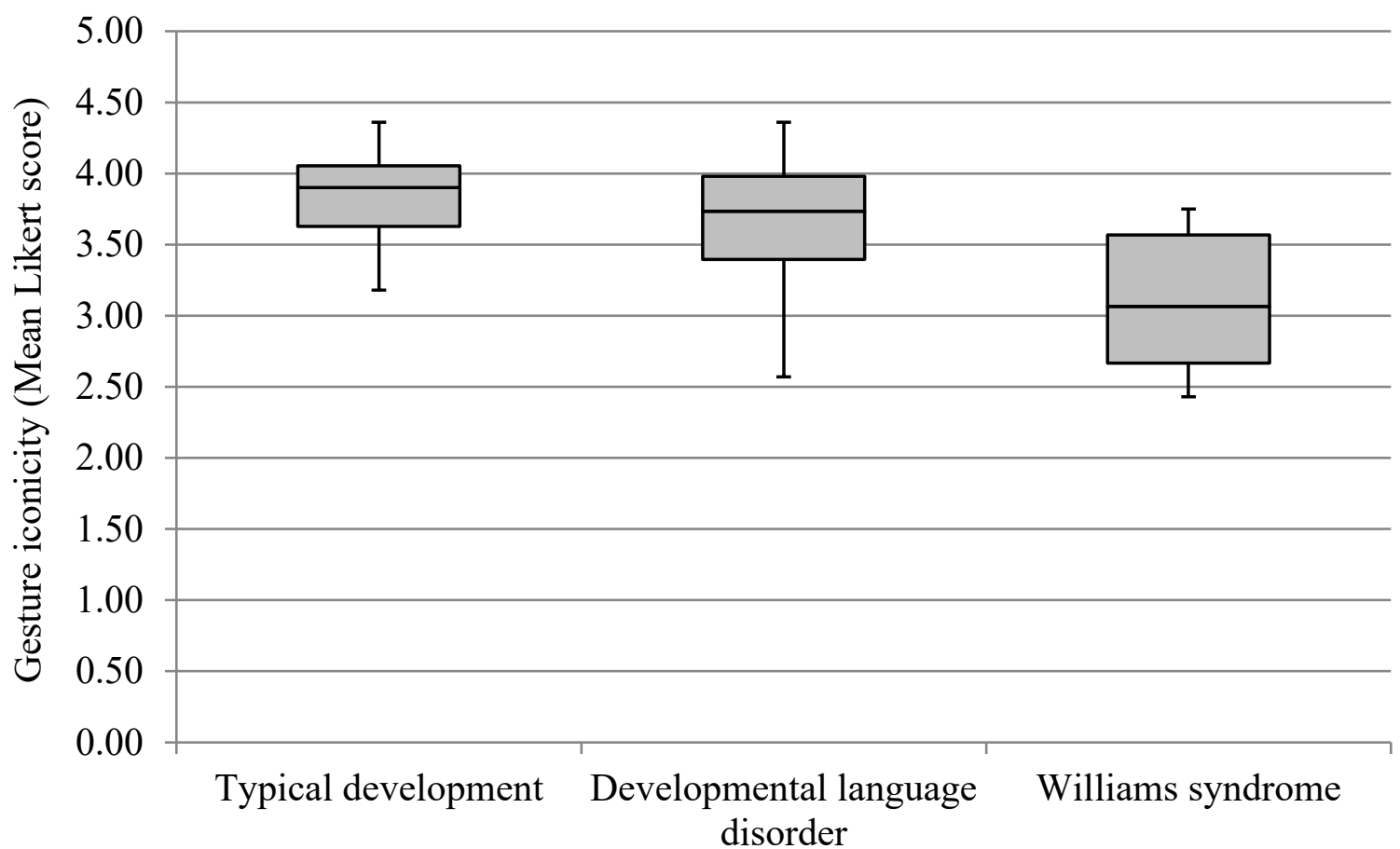

Participant group

Figure 1. Pantomime iconicity ratings of participants with typical development, developmental language disorder, or Williams syndrome. 


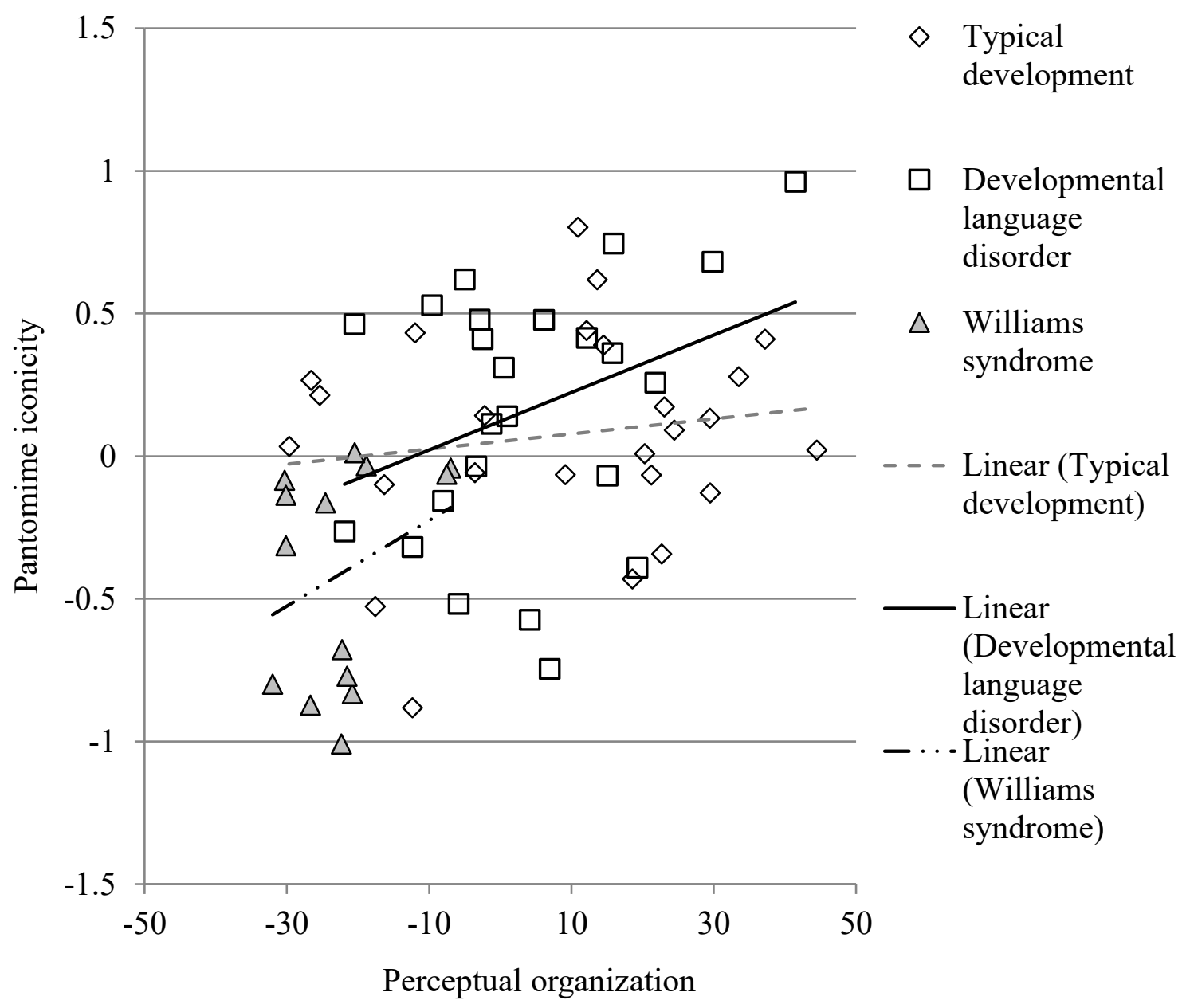

Figure 2. The partial correlation between perceptual organization and gesture iconicity, controlled for expressive vocabulary and semantic association. 


\section{Appendix A}

Exponential Regression Curves for the WISC-III Perceptual Organization Index Subtests

\begin{tabular}{lccccccc}
\hline Subtest & $R^{2}$ & $F$ & $d f 1$ & $d f 2$ & $p$ & Intercept & Coefficient \\
\hline Picture completion & .986 & 777.62 & 1 & 11 & $<.001$ & 30.57 & .073 \\
Picture arrangement & .991 & 2689.30 & 1 & 25 & $<.001$ & 53.03 & .029 \\
Block design & .982 & 1427.90 & 1 & 26 & $<.001$ & 48.69 & .022 \\
Object assembly & .996 & 3721.17 & 1 & 16 & $<.001$ & 27.24 & .052 \\
\hline Note. $d f 1=$ degrees of freedom for the numerator; $d f 2=$ degrees of freedom for the denominator
\end{tabular}


Appendix B

Scoring Rubric for the Pantomimes' Semantic Saliency

\begin{tabular}{|c|c|c|}
\hline Picture item & Feature 1 & Feature 2 \\
\hline House & Roof & $\begin{array}{l}\text { Square (part under the roof), opening } \\
\text { door, stepping inside }\end{array}$ \\
\hline Helicopter & Flying around, moving & Moving motion (propellor) \\
\hline Hammock & $\begin{array}{l}\text { Hanging in hammock } \\
\text { Rocking/moving side to side }\end{array}$ & Shape of hammock, tying the ends \\
\hline Tree & Leaves, branches, crown & Tree trunk \\
\hline Wheelchair & Wheels turning & $\begin{array}{l}\text { Sitting, driving another person in } \\
\text { wheelchair }\end{array}$ \\
\hline Pelican & Bird & Large beak \\
\hline Tennisracket & Swinging (racket) & Shape of racket, throwing ball in air \\
\hline Harmonica & Music, moving sideways & Mouth location \\
\hline Whistle & Blowing & Mouth location \\
\hline Igloo & Cold & Shape of igloo, stepping inside \\
\hline Mask & Face location, tying strings & Making faces, playing monster \\
\hline Cactus & Branches, shape & Thorns, pain, pricking \\
\hline Bed & Sleep & Shape of bed \\
\hline Funnel & Shape of funnel & Pooring \\
\hline Rhinoceros & Animal & Horn \\
\hline Comb & Hair location, combing & Shape of comb \\
\hline Saw & Moving back and forth & $\begin{array}{l}\text { Object being sawed (tree, arm, ...), shape } \\
\text { of saw }\end{array}$ \\
\hline Toothbrush & $\begin{array}{l}\text { Brushing teeth, mouth } \\
\text { location }\end{array}$ & Shape toothbrush \\
\hline Scissors & Opening and closing & Shape of scissors \\
\hline Broom & Moving back and forth & Dirty, picking up dirt from floor \\
\hline
\end{tabular}

Note. Each gesture in the elicitation task received a semantic saliency score. A new scoring rubric was developed. The gesture received a score of 0 when neither of the two listed elements was presented. A score of 1 meant that either elements from Feature 1 or elements from Feature 2 were represented in the gesture. A score of 2 signified that elements from both features could be deduced from the gesture. 